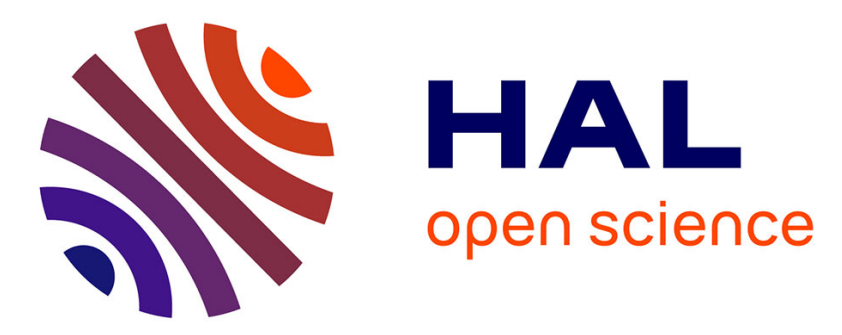

\title{
Data and models for exploring sustainability of human well-being in global environmental change
}

G. Deffuant, I. Alvarez, O. Barreteau, B. de Vries, B. Edmonds, N. Gilbert, N. Gotts, F. Jabot, S. Janssen, M. Hilden, et al.

\section{- To cite this version:}

G. Deffuant, I. Alvarez, O. Barreteau, B. de Vries, B. Edmonds, et al.. Data and models for exploring sustainability of human well-being in global environmental change. The European Physical Journal. Special Topics, 2012, 214 (1), p. 519 - p. 545. 10.1140/epjst/e2012-01704-2 . hal-01067995

\section{HAL Id: hal-01067995 \\ https://hal.science/hal-01067995}

Submitted on 24 Sep 2014

HAL is a multi-disciplinary open access archive for the deposit and dissemination of scientific research documents, whether they are published or not. The documents may come from teaching and research institutions in France or abroad, or from public or private research centers.
L'archive ouverte pluridisciplinaire HAL, est destinée au dépôt et à la diffusion de documents scientifiques de niveau recherche, publiés ou non, émanant des établissements d'enseignement et de recherche français ou étrangers, des laboratoires publics ou privés. 
EPJ manuscript No.

(will be inserted by the editor)

\title{
Data and Models for Exploring Sustainability of Human Well-being in Global Environmental Change
}

\author{
Guillaume Deffuant ${ }^{1, a}$, Isabelle Alvarez ${ }^{1}$, Olivier Barreteau ${ }^{1}$, Bert de Vries $^{2}$, Bruce \\ Edmonds $^{3}$, Nigel Gilbert ${ }^{4}$, Nick Gotts ${ }^{5}$, Franck Jabot ${ }^{1}$, Sanders Janssen ${ }^{6}$, Mikael \\ Hilden ${ }^{7}$, Olaf Kolditz ${ }^{8}$, Dave Murray-Rust ${ }^{9}$, Charles Rougé ${ }^{1}$, and Paul Smits ${ }^{10}$ \\ 1 National Research Institute of Science and Technology for Environment and Agriculture \\ (IRSTEA), France \\ 2 Netherlands Environmental Agency (PBL) - Utrecht Sustainability Institute (USI), Nether- \\ lands \\ 3 Center for Policy Modelling, Manchester, UK \\ ${ }^{4}$ Centre for Research in Social Simulation, University of Surrey, UK \\ 5 The James Hutton Institute, Aberdeen, Scotland \\ 6 Alterra, Wageningen, Netherlands, \\ 7 The Finninsh Environment Institute, SYKE, Finland \\ 8 Helmholtz Centre for Environmental Research (UFZ), Germany \\ ${ }^{9}$ University of Edinburgh, Scotland \\ 10 Joint Research Centre, Institute for Environment and Sustainability, Italy
}

\begin{abstract}
This position paper proposes a vision for the research activity about sustainability in global environmental change (GEC) taking place in the FuturICT flagship project. This activity will be organised in an "Exploratory", gathering a core network of European scientists from ICT, social simulation, complex systems, economics, demographics, Earth system science. These research teams will collaborate in building a self-organising network of data sources and models about GEC and in using new facilities fostering stakeholder participation. We develop examples of concrete directions for this research: world wide virtual population with demographic and some economic descriptors, ecosystem services production and distribution, governance systems at various scales.
\end{abstract}

\section{Introduction}

In this position paper, we draw a first outline of FuturICT-GEC, the activity within the FuturICT flagship that will provide new tools for addressing the challenges global environmental change (GEC) poses for the sustainability of human well-being.

The global environmental change refers to rapid changes in land-use, biogeochemical cycles, climate and biodiversity now occurring on an unprecedented scale in the earth system. Awareness of these changes and their associated threats has been growing in the last decades. In 1972 universal concern about the health and sustainable

\footnotetext{
a e-mail: guillaume.deffuant@irstea.fr
} 
use of the planet and its resources resulted in the United Nations conference on the Human Environment in Stockholm, Sweden. Since then, many such conferences have taken place, mobilising wider and wider audiences.

A wide community of researchers is now mobilised and organised in global networks for measuring and understanding GEC. The best organised is the Intergovernmental Panel on Climate Change (IPPC), which mobilises a large number of researchers to scrutinize research results about climate change in a broad sense. The International Resource Panel and the Intergovernmental Platform on Biodiversity and Ecosystem Services use similar approaches but still operate on a more modest scale. The International Council for Science's Global Environmental Change Programme coordinates a wide range of research in a multi-disciplinary partnership. Europe is rich in research and innovation organisations, collaborating with policy makers and the private sector at various levels, such as the Partnership for European Environmental Research (PEER), the Climate Knowledge Innovation Community, and the European Environment Agency (EEA). The research conducted in the context of GEC can be classified into two main strands: earth system dynamics, and its two-way interactions with human social dynamics.

- Earth system dynamics concerns physical, chemical, and biological aspects of geosphere-biosphere interactions, climate, soil erosion, water cycles, biodiversity and oceans. The Earth is considered as a complex biogeochemical system, in which a local change in a specific aspect (such as ozone depletion) can have dramatic impacts on the dynamical regimes of the system. The scientific effort aims at increasing our knowledge about both local mechanisms and their long range interactions.

- Human social dynamics interact with the Earth system dynamics as never before. This interaction follows two directions: the human social-economic dynamics that influence the Earth system, and the Earth system dynamics impacting human social-economic dynamics. Obvious examples of the former include demographics. In its recent projections, the UN's medium scenario is that the world population will grow to 9 billion individuals by 2050, and 10 billion by 2100 . In the high fertility variant, the world population would reach more than 15 billion by 2100 [1]. From the population increase together with increasing per capita demand, one can estimate an increase of $50 \%$ and $30 \%$ respectively for energy and water demand by the time the population reaches 8 billion (expected in 2024) compared with the situation of 2009 [2]. The UN Food and Agriculture Organization (FAO) projects that demand for cereals will increase by $70 \%$ by 2050, and will double in developing countries. Expected changes in economic activity, consumption standards, landuse change, and urbanisation all tend to aggravate the stresses on freshwater and food systems [3]. Conversely, this research strand also addresses the potential effects of GEC on human well-being, through catastrophic weather events, water scarcity or decreasing food security.

In fact, both aforementioned strands are increasingly linked on a wide range of scales, so that we can now refer to a coupled human-natural system [4]. Thus, both research strands and their connections are essential to finding the path to a world development that enhances and sustains human well being and potentialities within planetary boundaries.

FuturICT aims to achieve major breakthroughs in the second research strand mentioned above, and it will organise a specific Exploratory of GEC to this purpose. This position paper draws a first roadmap for this activity. We first propose a vision, summarising our major options (section 2). Then, we underline the need for new ICT tools to be developed in FuturICT to foster cumulative, cooperative and competitive effects in modelling various aspects of GEC (section 3). Then, we give examples of 
research directions related to GEC in which FuturICT tools would be particularly relevant. These examples cover modelling socio-ecosystem dynamics such as: population behaviours contributing to GEC and risks to well-being (section 4), ecosystem services production and distribution (section 5), and governance systems (section 6). The final section stresses the collaborations that FuturICT-GEC will organise, both inside and outside FuturICT.

\section{Vision}

The activity of FuturICT-GEC will be organised around the following goals:

- Finding extensive new sources of data about the human dimension of GEC (demography, migration, consumption, socio-economic processes framing consumption, governance, etc.), and deriving robust comprehensive views of the global state from those data, and to visualise the results. This will be part of the Planetary Nervous System of FuturICT [5].

- Using the knowledge extracted from these data to feeding different models of social dynamics related to various aspects of GEC to allow policy makers and citizens to explore possible futures and better understand past trends. These include production and consumption of various agricultural products, food systems, water and energy consumption, the impact of shortages on well-being and potential socioeconomic changes, ecosystem services production and distribution, and natural hazard management. This will be part of the Living Earth Simulator of FuturICT [6]. It should be underlined that we expect the system to include a multiplicity of models and data sources, corresponding to different problems and questions, and developed by a large scientific community (wider than FuturICT itself).

- Organising the interactions between these models and data sources, as well as appropriate kinds of user queries.

- Including the participation of stakeholders and decision makers at various stages of the modelling process, in order to incorporate some of their specific knowledge. In this way the work will better comply with the needs of potential users and will allow testing proposed new policies using simulation. This will be part of FuturICT's Global Participatory Platform [7].

In this activity, we will also include models of Earth system dynamics (the first research strand mentioned above), into FuturICT data and model facilities, through appropriate collaborations. The advantage of such an extension is obvious: it would make it possible to derive projections of the coupling between social dynamics and earth system biogeochemical dynamics. The ICT challenges related to this extension are strongly related to the ones that FuturICT already plans to address for large social system models: coordinating numerous networks of models and data sources in a coherent way framed by the requests of users, as developed in several papers of this special issue [5-7].

The Exploratory of GEC settles a collaboration between a core set of research teams in ICT, complex systems, social simulation from FuturICT and a set of partners specialised in research about GEC and Earth system science. Together, they will bootstrap the system of network and data sources of the domain with the aim to attract an increasing number of other users. 


\section{Towards a global self-organising system of models and data sources about GEC}

This section describes the state of the art in modelling for understanding and mitigating GEC, and how FuturICT situates itself in this context.

\subsection{Proliferating models based on more and more data}

The Limits to Growth report to the Club of Rome [8] may be regarded as an early ancestor of the FuturICT-Exploratory of GEC. Indeed, this book presented the first attempt to use computer simulations to anticipate our global future. Its predictions were very pessimistic and warned about the risk of a collapse of humanity if mechanisms to control its growth were not implemented. It had a huge impact in the media, partly because of the novelty of using computers to make global predictions. Soon after its publication, prominent economists, scientists and political figures strongly criticized The Limits to Growth, which discredited this type of project for about two decades. However, recent analyses conclude that the warnings that The Limits to Growth had given remain relevant for today's world [9,10]. According to Atkinson [11], the key message of The Limits to Growth's is the critical need to understand global dynamics in terms of complex, interconnected systems. FuturICT responds to this message and fully exploits the new ICT approaches that have been developed in the 40 years since The Limits to Growth.

One major change is the tremendous capacity we now have for gathering huge amounts of precise data about the Earth and human activities in a single information system, with facilities for their consultation. The "Digital Earth" idea launched in 1998 by American Vice-President Al Gore, integrates a gargantuan amount of georeferenced data combining multi-resolution, three dimensional and dynamic features, with a high-level integration of Earth science, space science, and information science. The 2009 Beijing Declaration on Digital Earth states: "Significant global-scale developments on Digital Earth science and technology have been made over the past ten years, and parallel advances in space information technology, communication network technology, high-performance computing, and Earth System Science have resulted in the rise of a Digital Earth data-sharing platform for public and commercial purposes, so that now Digital Earth is accessible by hundreds of millions, thus changing the production and lifestyle of mankind". Actually several attempts to develop a digital Earth are taking place over the world, some in purely scientific contexts, others with commercial goals $[12,13]$.

In addition to these data systems and large historical datasets, an increasing number of models are developed to simulate the key processes of GEC. In particular, Integrated Assessment Models of Global Change (IAM-GC) are an important instrument in the attempt to grasp global change processes in an integrated systems context [14-16]. The emphasis in these models has been and still is on the biophysical/geographical description of subsystems, such as the material stocks and flows of key elements (carbon, nitrogen, phosphorous) and the various stocks and flows of water. The representation of interactions with human dynamics - the topic of economic and social sciences - is usually confined to linkages with population density data through the use of stylized facts about resource use and waste flows, plus linkages with traditional (CGE) macro-economic growth models. The latter have become prominent in the assessment of costs and benefits of climate change, despite widespread doubts about their usefulness.

Agent based models (ABMs) aim at introducing agent behaviours that are closer to those described in sociological studies than the totally rational agents of traditional 
economic theory (e.g. [17]). Socio-ecological systems (SES) $[18,19]$ model societal and ecological systems in interaction [20]. SES concepts can be applied at multiple scales, but there is a strong argument that a global scale analysis is necessary [21]. When dealing with these complex interacting systems, ABMs provide an intuitive way to model the linkages and human decision-making processes. ABMs have been applied to many aspects of land-use modelling and ecosystem management [22-24]. The increasing empirical grounding of ABMs [25] supports their use in carrying out detailed modelling around ecosystem service provision and SESs at a landscape scale [26]. The direct correspondence between actors and agents allows for many aspects of human decision-making to be modelled, and for a range of different decision-making strategies to be used [17]. This makes ABMs particularly appropriate for SES modelling as they can take into account non-financial mechanisms, including multiple preferences, complex behavioural rules, and the social norms which are necessary to understand policy uptake and common pool resource situations $[27,28]$.

While existing EU FP-7 projects such as VOLANTE (www.volante-project.eu/, [29]) are attempting to use ABMs to model land use transitions at a European scale, the development of truly global ABMs has yet to reach its full potential. In part, this is due to the complexities involved in scaling-up and scaling-down existing models [17], and in particular the modelling of institutional agents. Another issue is the complexity of dealing with calibration and validation of ABMs; while some form of sensitivity analysis is already used in ABM assessment [30-32], the type of global sensitivity analysis [33] necessary to properly engage with these models is still an active research area, often limited by the computational cost of the necessary model runs [34]. The FuturICT Living Earth Simulator will provide a computational environment that supports this kind of structured large-scale investigation of complex model behaviour.

\subsection{Meta-models and toy models}

Frequently, existing models of socio-ecosystems are extended with ever more spatial and process detail. This causes a rapid increase in data requirements, while the model outcomes become more detailed but not necessarily more accurate. This is one of the areas where computational science can contribute with better algorithms to assess model outcomes in relation to data reliability and completeness. The more serious shortcomings of existing modelling techniques, however, are of a structural nature: the failure to adequately capture nonlinear feedbacks within resource and environmental systems and between human societies and these systems. To address these shortcomings, there are two possible approaches that fit well into the Exploratory of GEC project.

The first avenue is to collect and develop toy models, or simplified metamodels, sometimes also called "model emulators" [35], of existing expert models, approaching the behaviour of the complex models. These models are simpler to study, through systematic experiments to analyze the consequences of, for instance, the possibility of nonlinear feedbacks and couplings. The acquired knowledge is essential for the choices made later in more complex models. The set of simple models constructed in the past few decades under the heading of complex system science is impressive [36]. Improved understanding of human responses to global environmental change can be incorporated into the systematic collection of and experimentation with cellular-automata and agent-based simulation models, especially if these approaches are complemented by theoretical insights such as studying of the role of non-linearities or of dependency to initial conditions.

This approach requires enlarged datasets with more historical depth, along the lines of, for instance, the CLIO-INFRA project on long-term economic and social 
data collection (www.clio-infra.eu). It also demands further conceptual refinements in several areas, in order to develop tractable yet realistic models of interesting phenomena at the intersection between human behaviour and environmental change. Examples of research areas where such complex systems (meta)models can make significant contributions are:

- the existence of nonlinear (eco)system dynamics (e.g. [37,38]), in particular the consequences for local populations of associated regime shifts in (semi-)arid regions (see e.g. [39]);

- the role of financial, trade and innovation mechanisms and the responses to environmental deterioration seen in the evolution of the global agro-food system $[40$, $41]^{1}$;

- the connection between population dynamics, and air pollution and other global environmental change processes ${ }^{2}$;

- the behavioural dynamics of resource use, notably of (ground)water (see e.g. [42, $43]$ and of (renewable) energy resources .

The development and use of such (meta)models in connection with large-scale IAM-GC expert models can teach us more about the role in global environmental change of such important social dynamics as competition-cooperation in managing the global commons, and about the characteristics of innovation diffusion with respect to the envisaged transition to sustainability. For further details on such efforts see [36].

\subsection{Participatory processes}

A second avenue to address the aforementioned shortcomings is to engage decision makers and stakeholders in interactive model use experiments. Traditionally there has been a sharp divide between the policy making process and that of scientists trying to understand the systems with which policy is concerned. The policy making process might be hierarchical or distributed, but involves political discussion, the expression of different interests, consensus building, gathering of expert opinion and negotiation. The world of science is often seen to be characterised by data gathering, precise mathematical models and comparatively large independence of particular interests and objectivity. When scientists are asked to provide policy recommendations, their reasoning and especially the modelling process generally remain opaque to outsiders. However a number of developments are starting to bridge this divide.

The participation of stakeholders (including policy people) is increasingly being brought into the scientific modelling process to inform the micro-specification and validation of models (in addition to the goal), and thus improve them [44]. Complex social and environmental processes are often hugely varied and context dependent at the micro level, meaning that the relatively simple and uniform models of behaviour of past practice are open to being enriched by input from those that are best informed about them (the stakeholders). Furthermore, visualisations of simulations can often help to elicit useful criticisms of the feasibility of resulting simulation trajectories [ 45 , 46].

\footnotetext{
1 see e.g. http://www.eururalis.eu/) and the INSITE-project http://www.euclidnetwork.eu/pages/en/the-innovation-society-sustainability-and-ictinsite.html

${ }^{2}$ see WHO Global Burden of Disease project and Phoenix population model http://themasites.pbl.nl/en/themasites/phoenix/index.html
} 
On the other hand the modelling process is being increasingly brought into the policy discussion and making process, opening up the "black box" of policy modelling and involving scientists more in the wider process. Participatory approaches to simulation can make the goal and design of simulations more open to input and control from the world of policy and the public. Crowd-sourcing, where the data and opinions of many people are collected and combined can be a powerful approach to pinpointing emerging local areas of concern as well as to understanding and predicting complex social outcomes. It can be a complement to agent-based simulation models. It requires a different and transparent set-up of simulation models. This direction of research is promising in view of the rapid progress in branches such as experimental and behavioural economic and social sciences (see e.g. Dynamics of Cooperation Networks and Institutions http://www.dyconi.nl/) and the potential contributions from social media use.

Thus there is an emergent "middle ground" of processes that are not purely policy nor objective science, but involve mixes of the two worlds. However, if they are not correctly conducted these processes mix heterogeneous sources of information, without metaknowledge on the uncertainty attached to it: participants can have mistaken perceptions or provide misleading information for strategic reasons. Therefore, the purpose of participation is rather to spot knowledge gaps, assess the diversity of views and identify indicators used by stakeholders in their own decision processes. Cautious capture of metaknowledge, for example, using logbooks as proposed by Etienne [47] is a way to correct misperceptions because it can give qualitative assessment of uncertainty attached to the information provided by the participants. Moreover, it is important to describe to the participants how their inputs will be used and to condition their participation on their agreement about this use, because then the participants are more confident in the process and more accurate in their input [48].

\subsection{A self-organising network of models and data sources}

In contrast to the time of The Limits to Growth, we are now entering an era of proliferation of models and data sources. Research on model bases dates back to the late eighties [49] and since then many attempts have been made at setting up " model bases " and metadata for models, especially in the Ecological Modelling area (see EcoBAS : http://ecobas.org). The TESS (Transactional Environmental Support System) FP7 European project is currently developing a data base of models and decision support systems in ecosystem services management, which currently includes 165 models (http://tess.ttu.ee) covering a wide variety of topics (agriculture, forestry, fishing, farming, heritage conservation, land-use planning, risk assessment, etc.) chosen among more than 2,400 examples collected from existing databases of environmental management models. Hence, the problem is now to organise an ICT system that facilitates access to models and data sources, their reuse in new models, both fair competition and cooperation between different projects. Such a system would indeed foster a more efficient cumulative scientific progress.

FuturICT will need to incorporate support for model comparison, and the replication and extension of modelling work by researchers other than the model's originators, including the integration of originally separate models across disciplinary boundaries. Provision will also be needed for recording the provenance of both data and models: where, when, how and by whom data was collected and checked, and models designed and built; and also the empirical and theoretical underpinnings of models. A number of initiatives aimed at providing such facilities have been developed within the agent-based modelling community in recent years. Notably the ODD protocol for describing individual-based and agent-based models [50] and the 
"MR POTATOHEAD" approach, based on formal ontologies expressed in the OWL language [51]. Work using ontologies and related tools and specifically designed to support evidence-based policy-making is also underway [52]. The platform developed in the EU project TaToo (http://www.tatoo-fp7.eu/tatooweb/), for semantic annotation of environmental resources, could also be useful in clarifying the modelling approaches. FutureICT-GEC will encourage modellers to make use of such tools in order to make their work more accessible and transparent.

The European Union (EU) has been successfully developing and implementing a multi-national, multi-purpose spatial data infrastructure through Directive 2007/2/EC of the European Parliament and of the Council of 14 March 2007 establishing an Infrastructure for Spatial Information in the European Community (INSPIRE). Through the INSPIRE Directive, interoperability is being achieved for a number of components, including metadata, network services, and data specifications for a large number of spatial data themes. In particular the INSPIRE standards for data (EC 2011) will be of utmost importance to FuturICT. Not only do they introduce a semantic harmonization that is paramount for pan-European and cross-border analyses, modelling and forecasting, but they also establish relationships between different data themes. World-wide, in the process leading up to the eye on earth summit, a white paper on Recommendations for the Technical Design of a Global Interoperable Information Network was put forward [53]. These recommendations will need to be considered and possibly integrated into the design of the Exploratory.

To make such a network of data and models a reality, a strong collaboration with ICT teams within FuturICT is needed in order to develop progressively a user friendly and flexible system that allow the researchers to easily integrate their models as well as reuse already existing models or results. There is a very important issue in defining the right metadata to require as well as in the procedures for including models, model results or data source in the system. The objective would be to make it similar (or better) as a publication for the researcher career. Peer reviewed process on the model design and results, and then statistics of use (similar to citations). This implies to provide the researchers with a strong incentive to participate in the development of the system. A system of commenting by experts and users should be included as well, because it is important that various users have some clues to navigate among the wide variety of models, data and results. The quality of the navigator itself within this huge diversity of models will also be a key to the success.

Within FuturICT, the Living Earth Simulator will build on these advances to organise a constantly evolving network of model results and data sources, at planetary scale, accessible via the Internet through specific facilities. The Living Earth Simulator will allow the research community to enrich it progressively with new models and new sources of data. Moreover, results of the simulations should be accessible to a variety of users (including the general public) via the Internet, with an appropriate interface to navigate among models, hypotheses, scenarios behind the simulation, and comments from peers and users.

Collectively we have come a long way since The Limits to Growth. But we need to make the next steps to bring it all to fruition. We now give more precise examples of the directions of work that we envisage. 


\section{Modelling populations behaviours contributing to GEC and risks on their well-being}

\subsection{An Individual-based virtual population statistically valid from local to global scales}

The Exploratory of GEC will innovate by developing a world-wide virtual and individualbased population at local level (municipality). This virtual population will consist of virtual individuals, generated in a way that respects demographic statistics at different scales. It will take into account the uncertainties in the data by generating several different populations reflecting these uncertainties, providing several possible inputs for models. The individuals will be described using a limited set of relevant socio-economic variables (age, education level, activity, etc.) and will be grouped into households. The methods for generating such virtual populations are available (e.g. [54]) and they are beginning to be applied in USA and Europe, but not at the global level. Moreover, they are in general part of a single project, and are therefore developed to match its particular goals and constraints, not to be made available to the research community.

The availability of such virtual populations (constantly updated and improved by contributing researchers) is a very important first step in making downscaled analyses of population relationships to GEC, and further for developing dynamical models anticipating their evolution. The distributed organisation of this ICT setting will allow different research teams to develop such analyses in parallel for different regions or localities (and potentially to propose competing analyses for the same regions). Moreover, generated populations are of great interest for other topics of FuturICT, in particular for economics and health.

\subsection{Data fusion for downscaled analyses of population contribution and exposure to GEC}

The next step is to associate the individuals and households of these virtual populations with data sets about their potential contribution to GEC, such as consumption of water, food and energy. These data can come from various sources: distribution companies (energy, food, water), public statistics bodies, specific studies following subsamples in detail, or Internet crowd-sourcing. A common approach is to determine profiles of consumers and then to relate them statistically with the variables describing individuals or households. It is for instance observed that patterns of food and water consumption evolve with wealth (e.g., food consumption in developing countries is shifting from cereals to fruits, vegetables, meat and oils, [55]).

This is a problem of data fusion which is one of the topics to be treated by the Planetary Nervous System. FuturICT-GEC will collaborate with ICT researchers involved in otherparts of FuturICT to perform this data fusion. Of course in some cases the work will require new data collection or the definition of proxies. Such work will be carried out in collaboration with specialised social science teams, and could be the subject of new experiments collecting new data on reactions of subjects to specific situations, on the participatory platform. The results of these analyses could be of interest to citizens, policy makers and companies involved in the production or distribution of the goods considered. The other challenge is to associate these virtual populations with their exposure to potentially negative effects of GEC and to evaluate more precisely some objective parameters of impact on their well-being [56]. Defining well-being is the subject of much discussion: the GEO-4 report ([57] p.13), distinguishes three views which have different implications for the environment. The 
first stresses people's resources and assets, the second the subjective feelings of people about their life, and the third what people are able to be and do. In the Millennium Assessment (2003), human well-being encompasses personal and environmental security, access to materials for a good life, good health and good social relations, all of which are closely related to each other.

In relation to GEC, well-being should be associated with data about access to energy, enough food, safe water, clean air, shelter with acceptable comfort, clothing and access to other goods. Social relations, which are often considered as an important part of well-being, can also be disrupted by GEC, in particular by urbanisation; although conversely, this can offer opportunities to escape oppressive social relations, particularly for women. We can address the question of social relations by trying to define typical social networks from specific surveys and studies of Internet data, or by identifying organised communities. One can expect these communities to be mostly localised, although conditions provide incentives for people to connect to connect at an unprecedented scale and to turn these connections into action. For example, in southern Europe the "indignados" movement has tried to influence the political development and the "Arab Spring" made a change relying strongly on new communication tools. Also in Russia social movements are gathering force using new communication technology. In FuturICT, analysing and tracking new links that carry information on GEC and relevant action will be essential in efforts to understand how responses to GEC evolve.

Establishing robust statistical connections between individual and household characteristics, and data related to well-being, requires applying the methods worked out in the planetary nervous system. Some of these results could be checked in experiments on the participatory platform. Ultimately, these will allow us to analyse the exposure of populations to the negative effects of GEC at different levels of details and geographic scales.

This progressive development of downscaled analyses will be important for understanding how the contributions to and exposure to GEC, and more particularly degradations of well-being, vary across space and among different categories of the population. Such more detailed analyses are very important in framing political discussions and targeting policy measures more precisely.

\subsection{Micro-simulation of demographics at planetary scale}

The data collections, analyses and fusions previously mentioned will also define the basis for individual based dynamical models. The goal here is to go beyond the instantaneous pictures of the system given by the data analyses and to try to anticipate its future evolution under different scenario options (defined for instance by policy measures and economic context). This implies inclusion of mechanisms that determine behavioural changes in the model population, in first instance based on past data and the assumption of constancy of such mechanisms.

The first driver to include is demographic change: individuals get older, get married, divorced, have children, die. These dynamics will modify the households defined from the data. A common way to include demographics in an individual-based model is the so-called micro-simulation approach, in which life events occur to individuals according to conditional probabilities which are computed from time series data or specific surveys. Such models are currently developed at regional or national scales, for instance in Japan [58] or Sweden [59].

An important difficulty in this approach is to define the evolution of migration dynamics which can be impacted by a variety of events and by policy changes. Indeed, 
one has to make assumptions about how individuals and households decide to migrate. This, of course, may be connected with socio-economic attributes, that hence should be included in the dynamical model. Moreover, there are often probabilities or parameters affecting the dynamics that cannot be derived directly from the data [60]. It is thus necessary to compute them by calibration on time series data. The reliability of projections will then depend on assuming at least as an initial hypothesis that the statistical relations between variables in these time series data will continue to hold. This is far from a trivial assumption, especially for complex systems, However, this does not render the projections useless, because:

1. We can seek to explain theoretically why they should be expected to remain the same, over the period of the projection.

2. The model itself should indicate an explanation of why the relations hold ; we can vary the model to get an idea what would happen if one or more of them ceased to hold.

3. Conversely, we may find that assuming they remain the same implies, if the model is correct, that some variables will inevitably take increasingly extreme values over time, without limit, we can then reasonably deduce that at some point the statistical relations will break down; and we can use the model to explore the range of possible ways this could occur.

4. We can use multiple time series from the past - the more widely the relations concerned hold, the stronger the expectation they will continue to do so.

The aim is to derive such a demographic micro-simulation model at world level. This would make it possible to anticipate downscaled demographic changes. Again, more precise anticipation of changes depending on locations and population categories are very important in targeting policies more precisely. Nevertheless, such an individual-based model should be considered as complementary to the more usual aggregated projections: it is often valuable to compare model results at different abstraction levels. In particular, the variability of the results obtained with microsimulation models, due to the probabilistic processes determining life events, enables evaluation of the uncertainties on the predictions.

\subsection{Coupling demography with behaviours contributing to GEC or with vulnerability to GEC}

Micro-simulation models of demography can be used as a starting point for implementing dynamical models of the contribution of populations to GEC. This requires reference to the data analyses generating the socio-economic characteristics of individuals while integrating them in households. Moreover, it requires elaborating rules for the evolution of individual and household consumption of the goods considered (different types of energy, food, water, etc.) as the individual or household situation evolves over time. Clearly an important point here is to include dynamics connected with the socio-economic paths of individuals (e.g. whether they are employed or not, if so in what type of job and with what level of salary, what assets they possess, etc.). Indeed, these attributes are important in evaluating consumption profiles. They also have a significant impact on migration decisions (e.g. rural exodus in the developing countries). In this respect, the Exploratory of GEC will collaborate with the economists in charge of the Exploratory on finance and economy in FuturICT and our aim is to jointly develop models of population demographic and economic evolution. Other behaviours (and their evolution) are more closely connected with social interactions and social values. The emerging methods of computational social science will address these aspects, for instance in innovation diffusion models (e.g. $[61,62])$. 
To anticipate the degradation of well-being by GEC, evaluating the evolution of the economic situations of individuals and households is crucial, because the world's poorest people depend primarily on environmental goods and services for their livelihoods. Specific studies from FuturICT-GEC models could be devoted to the impact on people's well-being of very significant increases in primary goods' prices (like the one which took place in 2008), and of freshwater prices. Furthermore, many communities in both developing and developed countries derive their income from environmental resources, which include fisheries, non-timber forest products and wildlife [57]. These communities are directly impacted when GEC damages their sources of income.

As mentioned previously, well-being is also related to the quality of social relations. Hence a further step in modelling that needs to be explored in FuturICT activity related to GEC is modelling the dynamics of communities' evolution. This implies designing mechanisms for the evolution of social networks, at local and more global levels. Such mechanisms are already being studied from data, and this is one particularly active research topic of computational social science. Large scale data collection settings on the Internet could be imagined to ground the considered models.

\section{Ecosystem services production and distribution}

In this section, we consider the study of the socio-economic systems which are directly related to the production, exploitation and distribution of ecosystem services, in the perspective of computational social science. We give some examples of research directions without aiming to be exhaustive. In the same spirit as in the previous section, FuturICT will build on some ICT facilities to generate core sets of models and approaches that attract the activities of other research groups and enrich the network of models and data.

\subsection{Land}

Over the last 20 years, increasing human population, economic development and emerging global markets have driven unprecedented land-use change. The most dynamic changes have been in forest cover and composition, expansion and intensification of cropland, and the growth of urban areas. Even more significant than the change in cropland area, is that land-use intensity has increased dramatically since 1987, resulting in more production per hectare. The enormous increase in the production of farm and forest has brought greater wealth and more secure livelihoods for billions, but often at the cost of land degradation, biodiversity loss and disruption of water and nutrient cycles [57]. Irrigation is one major driver of that evolution. Irrigated land produces 30-40 per cent of global farm output, and a far higher proportion of high-value crops, from less than $10 \%$ of the farmed area. Increasing water withdrawals for irrigation increase the likelihood of salinity. Worldwide, some 20 per cent of irrigated land (450 $\left.000 \mathrm{~km}^{2}\right)$ is salt-affected, with $2500-5000 \mathrm{~km}^{2}$ lost from production every year as a result of salinity $[63,64]$. However, it is widely recognised that there are large opportunities to increase water use efficiency.

Projects for the treatment of new data about land use and the development of ambitious models of land use change are numerous. In Europe for instance, integrated projects like SENSOR and SEAMLESS gathered large numbers of researchers from different fields of expertise to develop such models. However, it appears that these models are still of rather limited use and the models do not evolve rapidly. FuturICT will have to create a more open community of modellers that can use and explore data and ensure a continuous improvement of the models. 
Land-use change modelling is often carried out by treating whole countries or large regions as if they were a single farm, using techniques such as linear programming to determine the combination of land uses that is likely to be most profitable in future (e.g. [65]). Such techniques work reasonably well over periods of a few years (during which the drivers of land-use change can be assumed to remain largely the same), but they ignore the heterogeneity of real farm businesses, and the fact that small farmers in particular are not generally simple profit maximisers: they are often emotionally attached to their land and to particular land-uses, reluctant to sell land or abandon a tenancy even when this would be economically rational, and concerned to be seen as a "good farmer" by their peers [66]. They often combine farming with other economic activities, grow a range of crops to take into account uncertainties, including institutional ones, and are wary of making irreversible choices. Over the last two decades, therefore, there has been an increasing use of agent-based simulation to study land-use change issues such as innovation and imitation [67], deforestation and reafforestation [68], the management of limited water resources [69], the relationship between farmers and nomadic herders [70], and urban sprawl [71]. In recent years, there has been an increasing emphasis on the need to validate agent-based models of land-use change with detailed empirical information [72]. Much of this work has been undertaken in collaboration with small farm households in developing countries, and this has frequently involved the use of role-playing games in order to elicit details of such households' decision-making processes [23]. In contrast, there have been few if any attempts to apply agent-based techniques to land-use on a national or larger scale: until recently the computational resources needed for such an approach have not been available to many - if any - researchers in the area; and the demand such models would have for empirical data still poses a serious constraint.

The ambition of FuturICT is to build on these achievements with the following objectives:

- Creating a closer relation between data about land-use, expertise (including lay expertise available through participatory settings) and data about socio-economic agents (farmers and foresters in particular) that are responsible for land-use change.

- Defining new protocols of data collection in collaboration with social scientists that shed light on the connection between data about land-use and decision making processes of agents.

- Developing new data-intensive dynamic models based on extensive data on landuse change related to agent decision-making processes. Such models could be developed at different scales and different levels of abstraction.

- Using the population models mentioned in the previous section (integrating demographics and economic activities) to study the influence of individual and household mobility on changing urban / rural relationships.

\subsection{Food systems}

The Global Environmental Change and Food System (GEFACS) project has developed a comprehensive framework to describe all the activities, processes and outcomes in modern food systems and all possible interactions with GEC (see [73] for details). Several rigorous conceptual frameworks have inspired the concept of a "food system". The commodity system analysis (CSA) $[74,75]$ takes a single commodity as departure point, and covers production practices, grower organisations, labour, marketing and distribution networks, consumer and community cultures, scale, relations with the state, and commodity culture. The global production network (GPN) approach builds on the CSA by acknowledging global interdependency [76]. The GPN 
highlights the importance of socio-technical system to any endeavour, temporal and spatial specificity and the difficulty of generalising across commodity sectors. The food regimes approach [77] is strongly influenced by the CSA concept but tries to put the analysis in a historical perspective, focusing on the evolution of value relations.

Food system activities include producing, processing, packaging, distributing, retailing and finally consuming food. Food system outcomes have an impact on social welfare, food security and environmental welfare. Food system dynamics both depend on and impact both socio-economic evolution (demographics, economics, cultural values etc.), and GEC (land cover and soils, atmosphere, water availability and quality, biodiversity etc.) [78].

Food systems are complex dynamical systems. Agriculture is no longer the primary income generating (or labour employing) activity in food supply chains either globally or in many developed countries. Processing, packaging and distributing have grown in importance. However, many developing countries still do depend heavily on agriculture. Globalization has connected commodity markets and food security outcomes across space and over time [79]. Much more agricultural production is traded than 30 years ago. Food-price shocks in one country or region have ripple effects elsewhere, as the commodity price increases of 2007-8 have shown. Food systems are multi-scale (spatial, temporal, jurisdictional and institutional), and globalisation has altered many cross scale interactions, generally increasing them [80,81,21].

In order to assess the sustainability and equity of access to food, research approaches need to be capable of capturing the relationships between the components of a food system. These include the biophysical resources which make food production possible, the resource-use demands of food processors and retailers, and consumer behaviour, including food preferences, preparation and intra-household distribution patterns. Such a comprehensive approach will also contribute to understanding the multiple ways in which food systems interact with GEC, and the consequences of these interactions for food security.

The collaboration between ICT, complexity research and computational social sciences in FuturICT appears particularly appropriate to meet this challenge. The data intensive modelling approach developed in FuturICT would make available new means for more precise analyses of past dynamics in food systems (or parts of them), and the exploration of future scenarios. In general, the scientific advances that FuturICT will aim at are related to the development of more systematic data gathering from the social-technical systems considered (tracing products from production to consumption), the use of new tools for analysing and representing such data (such as representations of complex networks of interactions), and the representation of power and value interactions, using recently developed concepts and methods of computational social science.

Practically, this approach could start by focusing on specific food products, as in commodity system analysis. In addition to understanding possible hidden or counterintuitive dynamical process through extensive data analyses and intensive simulations, the research will have more specific targets such as:

- Embodied carbon and virtual water. "Embodied carbon" refers to as the greenhouse gases emitted in the process of making a product and similar approaches can be applied to water use. Behind both concepts is the need to use whole lifecycle analysis (LCA) to calculate the impact of food production, packaging and distribution on GEC. Starting initially with carbon, the approach tends to be enlarged to water and nitrogen "embedded" in the commodities and even to social effects in "social LCA" [82]. For example, Galloway et al. [83] have developed a model to calculate the virtual trade in environmental degradation to produce and distribute meat. Research teams involved in LCA produce databases of standard contributions to be used when unfolding the various pathways, such as impacts 
of freshwater production [84]. More comprehensive modelling approaches developed in FuturICT could apply similar approaches to populations of local actors participating in the supply chain, and use advanced tracing product systems.

- Food security and integrated policy. In addition to the impact on GEC, FuturICTGEC models could address issues such as the impact on food security of different shocks to the system. In the case of the 2007-8 crisis, this impact was closely related to states setting up national tariff barriers and reducing their exports of grains, so exacerbating the crisis. The models could investigate the outcome of global coordination in such circumstances. In addition to the breakthroughs that can be expected in fruitful collaborations between ICT, complex system research and computational social science in modelling food systems, the major step forward is facilitating cumulative progress in the modelling effort, in contrast to the current situation, where each modelling project tends to build from scratch. This will progressively allow for an analysis of interdependencies between the different commodity systems. Again, we expect that series of models at different scales and levels of abstraction will be fruitful. The most fine-grained models will uncover potentially unexpected emerging dynamics, and make possible to develop more aggregated models incorporating these findings.

\subsection{Industrial ecosystems}

Major effects on the environment arise from industrial activities. Reductions in material and energy usage, re-use of by-products and waste, and lengthening of the lifespan of manufactured products can all have significant effects on ameliorating GEC. In order to achieve such reductions, it is necessary to understand the actual and potential linkages between firms, the supply chain, at the global, regional, and local levels and across industrial sectors. Such studies have been growing in number under the banner of 'Industrial Ecosystems'. An example of how such work can contribute to reducing GEC is the Industrial Symbiosis movement. This aims to connect firms so that what is to one merely a waste product of its processing becomes a material source for another (for instance, sub-standard and broken items from a ceramics factory can be recycled to make aggregate for concrete manufacture). Similarly, waste steam from a chemical process can be used to generate electricity, rather than being vented to the air. However, such inter-connections between industries can also lead to complex interdependencies that reduce resilience and leave firms vulnerable to shocks.

It is therefore important to examine the patterns of relationships in industrial supply chains, bearing in mind not only the flows of material and energy, but also the transfers of risks, the relative power of actors along the supply chain with the potential for either exploitation or benefit, and ownership and control structures. There are already some localised research efforts of this type (e.g. $\left.[85]^{3}\right)$, but there is a need for increased scale and ambition. This will require an international effort to obtain data on industrial processes, input-output matrices, and opportunities for symbiosis. In addition, there is a need for data on the environmental impact of industries and individual firms at a local level, and multi-scale models that can help to integrate these various types of data.

One of the most challenging areas that FuturICT will have to deal with is the emergence of innovations and industrial and societal transformations. Conceptual models for how transformations take place have been developed (e.g. [86]). FuturICT would allow capturing essential processes using data and models, thus allowing a systematic exploration of alternative transformation pathways and the factors affecting them.

\footnotetext{
3 ERIE http://www.erie.surrey.ac.uk
} 
In this research direction, a close collaboration with the FuturICT European Economic and Financial exploratory and the Technology exploratory will be particularly important.

\subsection{Water management and distribution systems}

The global impacts of human interventions in the water cycle, including land cover change, urbanisation, industrialisation and water resources development, are likely to surpass those of recent or anticipated climate change, at least over the next decades [87]. Water withdrawals for irrigation have increased dramatically, to about 70 per cent of global water withdrawals. One-tenth of the world's major rivers no longer reach the sea during some part of the year, because water is extracted upstream for irrigation or other uses [88].

Available water resources continue to decline as a result of excessive withdrawal of both surface- and ground-water, as well as decreased water run-off due to reduced precipitation and increased evaporation attributed to global warming. Already, in many parts of the world, such as West Asia, the Indo-Gangetic Plain, the North China Plain and the High Plains in North America, human water use exceeds annual average water replenishment. Use of freshwater for agriculture, industry and energy has increased markedly over the last 50 years [57].

By 2025, about 1.8 billion people will be living in countries or regions with absolute water scarcity, and two-thirds of the world population could be under conditions of water stress - the threshold for meeting the water requirements for agriculture, industry, domestic purposes, energy and the environment [89].

Water quality degradation from human activities continues to harm human and ecosystem health. Around 2.6 billion people live without adequate sanitation [90]. Three million people die from water-borne diseases each year in developing countries, the majority children under the age of five. Pollution from diffuse land sources, particularly agriculture and urban run-off, needs urgent action by governments and the agricultural sector. Pesticide pollution, endocrine-disrupting substances and suspended sediments are also hard to control [57]. Further, accidental and catastrophic industrial pollution of water is still a major threat, as shown recently in Hungary and China, as is past pollution remaining in sediments, such as PCB in major rivers. Overexploitation of coastal aquifers induces salt intrusion. Finally, water quality can also be affected by warming due to its use for cooling nuclear plants for example, damaging aquatic life.

Aquatic ecosystems continue to be heavily degraded, putting many ecosystem services at risk, including the sustainability of food supplies and biodiversity. Global marine and freshwater fisheries show large declines, caused mostly by persistent overfishing. Total marine catches are being sustained only by fishing ever further offshore and deeper in the oceans, and progressively lower in the food chain [57]. This situation is inducing local tensions across the world. They are magnified when they cross borders, inducing cascade effects. The Israel-Palestine case is a major example of this situation: political conflict and water scarcity narratives have generated a loss of access to water on the Palestinian side, with intensification of use on the remaining resources as a consequence.

Current trends are ambiguous, with development of gray water use for irrigation in order to cope with water scarcity, water is saved but the water cycle is sped up, potentially inducing concentration of pollutants. This is a typical case of new technologies enabling an increase of interactions between socio-technical and earth systems. Practical implementation of Integrated Water Resource Management (IWRM) at the basin scale, including conjunctive consideration of groundwater aquifers and downstream 
coastal areas, is a key response to freshwater scarcity and quality issues. There is evidence that IWRM at the basin scale, combining improved effluent treatment and wetland restoration with education and public awareness, is effective [57]. At EU level, the 2000 Water Framework Directive relies upon this paradigm. Networks of observatories have been established as interdisciplinary research programmes that aim to observe and explore the long-term ecological, social, and economic impacts of global change at the regional level (e.g. TERENO in Germany, [91]). The extensive data provided by these earth system observatories require adequate data management to appease the growing "data hunger" of models. High-performance computing and scientific visualization are crucial technical tools [92] supporting the process of living earth simulator development.

As an example, the International Water Research Alliance Saxony (IWAS) aims to contribute to an IWRM in hydrologically sensitive regions by developing specific system solutions as a response to water-related problems worldwide [93]. Overarching objectives are (1) to generate interdisciplinary system understanding for sustainable management of water resources in response to natural and social changes, (2) to develop and implement site-specific methods, models and technologies for water management, (3) to develop and apply site-specific management concepts and implementation strategies involving local governance structures and participatory processes, and (4) to contribute to the transfer of existing and newly acquired knowledge to the modelled regions (capacity development).

However water management at both national and global scales has mainly focused on two strands: "command and control" and integrated management, which have each had limited effect [94]. Regulation by incentives and contractual obligations has proven effective when a small number of occasional polluters exist with limited uncertainty about their actions, but it is less effective in situations of high uncertainty. Integrated management has mobilised multi-disciplinary knowledge to plan and coordinate policies impacting water by ensuring the agreement of the population through their participation in deciding measures at the watershed level. However, the effectiveness of this collaborative planning by basin is affected by other policies (employment, housing, agriculture, etc.) and it is vulnerable to uncertainties and the renewal of pollution issues. Resilience assessment provides tools to identify potential upcoming changes in river basins [95].

Research questions concerning worldwide water problems in the context of GEC will be tackled in FuturICT. Specific aspects of representative priority problems of water management could be examined in selected regions of Latin America (Brazil), the Middle East (Oman, Saudi Arabia), Eastern Europe (Ukraine), Central Asia (Mongolia), and South East Asia (Vietnam), where a pronounced sensitivity with regard to the aspects investigated can be identified. All relevant water compartments, managed systems (drinking water, wastewater, irrigation), the status and function of natural ecosystems, as well as anthropogenic influences (climate, land-use, etc.) will be investigated, where they appear most sensitive. In order to link the regions and form the potential to later integrate the findings into a holistic IWRM concept, certain aspects relevant to all model regions will be treated in cross-cutting subprojects. These aspects include systems analysis, scenario development and modelling, institutional prerequisites for water resources management, capacity development, and technology development and implementation [?].

FuturICT-GEC will build on the already significant experience in modelling for supporting IWRM and adaptive management at the basin scale. Such models are needed for a comprehensive view of all the actors depending on the water basin, and to project potential future evolution (for instance urbanisation, increase of agricultural needs for crops, etc.). 


\subsection{Forest and biodiversity}

Economic development has led and is still leading to a global crisis of biodiversity, so that planet Earth is experiencing its sixth mass extinction [96]. This has spurred the creation of the IPBES (Intergovernmental Science-Policy Platform on Biodiversity and Ecosystem Services), an analogue of the IPCC for biodiversity questions. Deforestation is going on at a roughly stable rate (FAO Global Forest Resources Assessment), while agricultural intensification and urbanization is increasing human pressure on natural systems. At the same time, the globalization of product exchanges, and the centralization of land exploitation following the emergence of large companies have created new pathways for environmental protection. Environmental certifications such as FSC and PEFC for forest products or organic farming for agricultural goods represent a growing part of the products in the world market [97]. Big companies are also aware of the benefits of environmental marketing [98]. Environmental preservation, marketing, consumer choices and public policies are thus profoundly intertwined, so that environmental protection has become a genuine complex system.

Developing scenarios on the future of biodiversity will require borrowing knowledge from many fields including ecology, climatology, demographics, geography, economics and other social sciences. The numerous interdependencies among these fields will need to be deciphered, and the effect of public policies on socio-ecological dynamics will need to be integrated in such scenarios [99]. While putting these fields together to build biodiversity scenarios is one of the current research frontiers in socioecological sciences (ERA-Net Biodiversa 2), these scenarios will constitute without doubt new complex systems needing to be understood so as to evaluate their robustness, sensitivity and reliability, and to design efficient mitigation measures. New tools will need to be developed in the field of complex systems, such as tools to analyze multi-level dynamics (European FP7 topic ICT-2011.9.7 Dynamics of Multi-Level Complex Systems), and tools to relate models to multiple types of data coming from multiple observational platforms.

FuturICT-GEC team will develop such tools within the FuturICT facilities and encourage other teams in the world to enrich this network of models and data sources.

\subsection{Natural hazards: floods and droughts}

Extreme events such as droughts, floods, or hurricanes, are expected to increase in intensity and frequency as an aspect of GEC [3], although statistical definition, physical understanding and forecast of climate extremes and their evolution still remain intrinsically challenging $[100,101]$. At the same time population in flood-prone areas is increasing. The long-term unpredictability of such events is part of the riddle water resources planners and managers have to solve, and the long-term engineering solutions that have been proven to work under a less variable climate may not apply any more [102]. One can contend that because of the economic cost (a six-fold increase was observed for flood cost in the US between 1932 and 1997 [103]) and the potential cascading social impacts of extreme climatic events, solutions cannot be found without an appropriate understanding of the social phenomena that come into play. In the case of floodplain management for instance, studies taking into account social aspects suggest that levees can foster a false sense of security which maximizes the impact of extreme flood events [104], while adaptive and decentralized prevention and mitigation strategies could prove successful in some communities [105]. Likewise, when water becomes scarce, the seemingly abundant supply made available by large-scale engineering solutions makes it more difficult to bring about much-needed behavioural changes in water consumption [106]. 
Creeping environmental changes are another type of natural hazard associated with GEC, and can occur in two different ways. First, they can gradually but directly force some ecosystems across thresholds and lead them to so-called catastrophic shifts (Schaeffer et al., 2001), which can durably or even irreversibly alter their properties. Such direct causes for natural hazards include unusually extreme heat and strong winds causing large-scale fires that destroy age-old forest over large areas, as happened in 2010 and 2011 in Russia. This type of hazard is often difficult to forecast the first time it happens, and as for other hazards, adaptive strategies should be tested and implemented to mitigate their effects.

Second, man-made changes can act indirectly by increasing the risk for natural hazards to take place, and increasing the value at risk in case of disaster, for example urbanisation often reduces water infiltration into the ground, and is therefore well known as a flood enhancer. Similarly, population density and economic growth can sometimes be blamed for structural water deficits even in the absence of drought in the meteorological sense. Hazard impact is often enhanced in highly populated areas, but such areas can also have a strong potential for remedial action, which can reduce hazard impact if appropriate action is taken. In the case of urban flooding, many solutions have been proposed or implemented, including collection into rain barrels or water holding rooftops, but they have often been studied piecemeal, and the engineering and social aspects are often found hard to integrate (e.g. [107]). For this reason, FuturICT will act to bring together the engineering and computational social science communities to better tackle the consequences of natural hazards:

- By providing social dynamics tools for engineers, planners and managers, towards designing better prevention, mitigation and adaptation strategies in the face of hazard of unpredictable magnitude.

- By collecting further knowledge on attitudes towards risk: what are the drivers for risk prone behaviors and for the adoption of new prevention settings.

- By providing computational social scientists with a large database of examples of strong disturbance of social systems for which the parameters, i.e. the chain of natural events, are given. Other types of social disturbances can then be compared to those caused by extreme events.

\section{Governance for sustainability and resilience}

\subsection{Earth system governance}

In the Earth System Governance Project of IDHP, Earth system governance is defined as the interrelated and increasingly integrated system of formal and informal rules, rule-making systems, and actor-networks at all levels of human society (from local to global) that are set up to steer societies towards preventing, mitigating, and adapting to global and local environmental change and, in particular, earth system transformation, within the normative context of sustainable development. The notion of governance refers to forms of steering that are less hierarchical than traditional governmental policy-making (even though most modern governance arrangements will also include some degree of hierarchy), rather decentralized, open to self-organization, and inclusive of non-state actors that range from industry and non-governmental organizations to scientists, indigenous communities, city governments and international organizations [108].

In the same report, Biermann et al. frame the research on Earth system governance into five main problems: 
- The architecture of earth system governance-this includes questions relating to the emergence, design and effectiveness of governance systems as well as the overall integration of global, regional, national and local governance.

- Understanding the agents that drive earth system governance and that need to be involved. The research gap here is especially the influence, roles and responsibilities of actors apart from national governments, such as business and non-profit organizations, the ways in which authority is granted to these agents, and how it is exercised.

- Understanding and further developing the adaptiveness of earth system governance. But what are the politics of adaptiveness? Which governance processes foster it? What attributes of governance systems enhance capacities to adapt? How, when and why does adaptiveness influence earth system governance?

- Ensuring the accountability and legitimacy of governance. What are the sources of accountability and legitimacy in earth system governance? What institutional designs can produce the accountability and legitimacy of earth system governance in a way that guarantees balances of interests and perspectives?

- Earth system governance is about the distribution of material and immaterial values as is any political activity. It is, in essence, a conflict about the access to goods and about their allocation-it is about justice, fairness, and equity. What (overarching) principles underlie allocation and access? How can allocation be reconciled with governance effectiveness?

Up to now modelling approaches have not much addressed governance questions. However, the general approach developed in FuturICT develops new means to meet this challenge and effectively collaborate with social sciences researchers. We now list some more precise illustrative examples:

- Complex system research develops more and more sophisticated tools for analysing networks of interactions (particularly those extracted from Internet data). These techniques could provide interesting views of the architecture of agents interacting in different aspects of Earth System governance, and of the role of different agents. The links studied could simply be references in documents, or more elaborated studies taking into account automatic treatments of the semantics of the documents.

- Computational social science is developing new methods for representing opinion dynamics in networks of agents that can take into account power relationships. Again, these models can be based on extensive data analyses. These models can be used to study the characteristics of different architectures, and their effectiveness in solving conflicts and in adapting to potential changes of context.

- Dynamical models of similar type can be used to study the views of different agents of the legitimacy of actors and whether different types of procedures and actions could improve their perceived legitimacy. The participatory platform can also be a very valuable tool to organise experiments on questions of legitimacy. Moreover, the FuturICT activity about crime and incivility should be involved to characterise the tendency for various institutional settings to generate more or less illegal behaviours.

The models developed should again be of different levels of details, in order to capture both the possible effects of interactions in detailed models, and clear theoretical interpretation of simpler analytical models focusing on specific identified complex dynamical effects. 


\subsection{Models and scenarios framing the future}

Beyond modelling and data, a major tool for work on governance in FuturICT will be the participatory platform. This platform will be the means to organise participative processes with decision makers, stakeholders and citizens. Such experiments, more or less extensively based on data and models, would concern not only Earth system governance, but also many other case studies of local governance.

An important development in participatory processes is the determination of relevant scenarios framing the future. The Limits to Growth [8] is part of a lineage of scenario development reaching back through The Year 2000 to postwar military strategizing and corporate development [109].

Rounsevell and Metzger [110] suggest that environmental science scenarios can be grouped into three types: exploratory scenarios develop a set of alternative, coherent futures to explore the range of possibilities-the IPCC SRES scenarios are a good example of this; normative scenarios work towards a desired future, and allow for multiple pathways to achieve particular goals; business-as-usual scenarios extrapolate current values and trends to explore the consequences of small changes with a short time horizon, typically to analyze regulatory and policy changes. Normative (or backcasting) scenarios are the least known. Here, the starting point is a desirable future state of affairs in the system to be modelled, perhaps expressed as a set of constraints; attempts would then be made (in conjunction with domain experts) to devise possible pathways from the current state to that desirable future, and agent-based modelling would then be used to test these scenarios, identifying the assumptions that must be made in order for them to be plausible. To the best of our knowledge, this approach has not yet been employed, although the "robust policy" approach of Bankes [111], in which large numbers of model runs are used to find a policy approach that will give acceptable results across a wide range of possible futures, is somewhat similar. This idea can be related to the framework of viability theory (see below).

Further, scenarios can also be probabilistic and participatory. Finally, there are desired qualities for scenarios to have: salience for decision maker's needs; scientific credibility and legitimacy, or incorporation of divergent values. For instance, one can note the evolution from a standard set of scenarios including "business as usual", optimistic and pessimistic to more elaborated sets such as the ones developed by IPCC, in order to attain more salience for policy makers: A1 for the market-oriented globalising world (Global Market); B2 its opposite: the community-oriented regionalising world (Caring Region); A2 the market-oriented protectionist world (Safe Region); and B1 the government-oriented globalising world (Global Solidarity). Such scenario names in this case used in UNEP's GEO, underline that scenarios are linking storylines with models and reflect a variety of different worldviews that are difficult to represent together in a single model [112]. Similarly, for local governance problems, it is important to design appropriate scenarios for the future.

\subsection{Resilience and sustainability}

Resilience and sustainability have become more and more important criteria in framing policies related to the environment. Indeed, ecologists had particularly developed and used the concept of resilience ([113] before it became more widely used for socioeco systems $[114,115]$. It is now the centre of interest of numerous researchers from various fields, who share a willingness to see their research be actually useful for policy makers and for society in general (the Resilience Alliance). Links between resilience, sustainability, stability and durability have been widely explored since the Brundtland Report [116], with work coming from several communities (economics, 
social science and ecology, see for example [117]). However, these concepts remain the subject of strong debates among scholars, and resilience can have precise mathematical definitions or broader qualitative meaning of a boundary concept, bridging different scientific disciplines [118]. Gotts [119] criticises the Resilience Alliance approach as both ahistorical and apolitical, ignoring both long-term directional change, and fundamental conflicts of interest within human societies. Other directions based on viability theory (Aubin 1991) are currently under development [120-122].

FuturICT will contribute to this research on resilience by including the point of view of complex system researchers and computational social scientists involved directly in FuturICT in the debates about these concepts and their possible use. FuturICT will offer a wide set of possible tests and experiments of the concept's variants on the models and data analyses carried out. In particular several directions can already be identified: (1) Sustainability of controlled systems. Large-scale data analyses can help to identify "control" variables, and models and simulation experiments will help to explore the impact of control policies based on these variables. (2) Resilience of wide communities or networks. FuturICT will provide the data and models on which sustainability and resilience can be studied on a multi-scale basis, which is very difficult to address even with full analytical dynamical systems. (3) Vulnerability of complex systems. FuturICT will provide enough real data analyses and simulations to explore the possible link between resilience and vulnerability in more than qualitative ways.

\section{Concluding remarks}

Even in the context of the very ambitious FuturICT project, this activity may appear even more so. It has the ambition to define a new approach that makes possible a much better cumulative scientific process in modelling activity related to GEC. If it succeeds, it will connect the major part of the world wide scientific modelling activity into a single very open, flexible and self-organising ICT system, as all websites are connected through the single system of the Internet. The main difference is that most of the models that will be part of the FuturICT-GEC system will have geography as a common reference, through which they could possibly be interconnected. Moreover, most of them will share at least some of their social components and dynamics, which provides another possibility for their interconnection. One important key to success for this initiative will be our capacity to implement modelling components that are both easily modified and improved, and readily used in larger models as basic modules to create a bootstrapping effect. Agreements should also be negotiated to include existing recognised models in the system. This is indeed part of the objective of scientifically cumulative modelling activity: that the strong investments leading to state of the art recognised models for specific dynamics would be reused by others, possibly in different contexts.

This implies a strong collaboration with ICT teams within FuturICT in order to develop progressively a user friendly and flexible system that allows researchers to easily integrate their models as well as reuse already existing models or results. This is of course important to provide the researchers with a strong incentive to participate in the development of the system. A system of commenting by experts and users should be included as well, because it is important that various users have some clues to navigate among the wide variety of models, data and results. Of course, the quality of the navigator itself within this huge diversity of models will also be a key to success. Other collaborations within FuturICT will be of great importance:

- Developing a virtual population at global scale, including demographic dynamics. This can become a common tool, interesting for different application domains 
of FuturICT including economy [?], epidemiology, energy [123], urbanisation and crime. This activity can benefit from the advances already made in epidemic models.

- Research on population, food and water consumption should be developed in close collaboration with the FuturICT activity in economics. This is also the case for the potential strong instabilities in food and water markets.

- Research on consumption should include the computational social sciences teams of FuturICT, changes in consumption being probably connected with deep changes in cultural values. These teams should also be mobilised for modelling networks of agents representing governance systems, as well as their perceived legitimacy by the public. Collaborating with the research on crime and illegal behaviour carried out in FuturICT will also be very important. Moreover, FuturICT-GEC will have to organise large-scale collaborations with research networks specialising in various aspects of GEC, in order to convince them to include their existing work into the FuturICT system, to collaborate in the development of new reusable models and to encourage them to include their future work in FuturICT systems (the planetary nervous system and living earth simulator). At world level, the Earth System Partnership includes numerous research networks that are interesting potential external partners, particularly those in the IHDP (Human Dimensions of GEC). In Europe, the Partnership for European Environmental Research (PEER) network and the knowledge and innovation community (KIC) on the environment are typical examples of such networks.

Finally, FuturICT-GEC should establish strong relations with stakeholders at various levels. At world level, it should establish links with, for example, the UN Environmental Program, UN Economic Commission for Europe and the World Bank, at EU level with the European Commission and at national level with the ministries of the states from Europe, United States and Asia.

A specific document about the organisation of this FuturICT-GEC will describe in details the organisation of the collaborations that will take place. Obviously this organisation will have a very important influence on the chances of success.

\section{Acknowledgement}

We warmly thank Rosaria Conte, Mette Termansen, Frank Schiller and Gérard Weisbuch for their remarks and suggestions on an earlier version of the paper. The publication of this work was partially supported by the European Union's Seventh Framework Programme (FP7/2007-2013) under grant agreement no.284709, a Coordination and Support Action in the Information and Communication Technologies activity area ('FuturICT' FET Flagship Pilot Project).

\section{References}

1. D. E. Bloom, "7 billion and counting," Science, vol. 333, pp. 562-569, 2011.

2. "Eea report. no 2/2009. water resources across europe confronting water scarcity and drought.," tech. rep., EEA, 2009.

3. "Climate change 2007: The physical science basis. summary for policymakers. contribution of working group 1, the fourth assessment report of the intergovernmental panel on climate change," tech. rep., IPCC, 2007.

4. V. Lucarini, "Towards a definition of climate science," International Journal of Environment and Pollution, pp. 413-422, 2002. 
5. F. Giannotti, D. Pedreschi, A. Pentland, P. Lukowicz, D. Kossmann, J. Corowley, and D. Helbing, "A planerary nervous system for social mining and collective awareness," Eur. Phys. J. Special Topics, vol. 214, 2012.

6. M. Paolucci, D. Kossman, R. Conte, P. Lulowicz, P. Argyrakis, A. Blandford, G. Bonelli, S. Anderson, S. de Freitas, B. Edmonds, N. Gilbert, M. Gross, J. Kohlhammer, P. Koumoutsakos, A. Krause, B. Linner, P. Slusallek, O. Sorkine, R. Sumner, and D. Helbing, "Towards a living earth simulator," Eur. Phys. J. Special Topics, vol. 214, 2012.

7. S. Buckingham Shum, K. Aberer, A. Schmidt, S. Bishop, P. Lukowicz, S. Anderson, Y. Charalabidid, J. Domingue, S. de Freitas, I. Dunwell, B. Edmonds, F. Grey, M. Haklay, M. Jelasity, A. Karpistenko, J. Kohlhammer, J. Lewis, J. Pitt, R. Sumner, and D. Helbing, "Towards a global participatory platform," Eur. Phys. J. Special Topics, vol. $214,2012$.

8. D. Meadows, D. Meadows, J. Randers, and W. Behrens III, The Limits to Growth. Universe Books, 1972.

9. G. Turner, "A comparison of the limits to growth with 30 years of reality," Global Environmental Change, vol. 18, pp. 397-411, 2008.

10. U. Bardi, The Limits To Growth Revisited. Springer, 2011.

11. A. Atkinson, Believing Cassandra: How to be an Optimist in a Pessimist's World. EarthScan, 2010.

12. M. Craglia, M. F. Goodchild, A. Annoni, G. Camara, M. Gould, W. Kuhn, D. Mark, I. Masser, D. Maguire, S. Liang, and E. Parsons, "Next-generation digital earth. a position paper from the vespucci initiative for the advancement of geographic information science," International Journal of Spatial Data Infrastructures Research, vol. 3, pp. 146-167, 2008.

13. H. Guo, Z. Liu, and L. Lu, "Digital earth: decadal experiences and some thoughts," International Journal of Digital Earth, vol. 3:1, pp. 31-46, 2010.

14. J. Rotmans and B. de Vries, Perspectives on Global Change - the TARGETS approach. Cambridge University Press, 1997.

15. "Growing within limits," tech. rep., Netherlands Environmental Assessment Agency (PBL), 2009

16. L. Bouwman, K. T., and K. Klein Goldewijk, "Integrated modelling of global environmental change an overview of image 2.4. mnp report.," tech. rep., Bilthoven, 2006.

17. M. Rounsevell, D. Robinson, and D. Murray-Rust, "From actors to agents in socio-ecological systems models.," Philosophical Transactions of Royal Society B, vol. 367(1586), pp. 259-269, 2011.

18. G. Gallopn, S. Funtowicz, M. O'Connor, and J. Ravetz, "Science for the 21st century: from social contract to the scientific core," International Journal of Social Science, vol. 168, pp. 219-229, 2001.

19. E. Ostrom, "A general framework for analyzing sustainability of social-ecological systems," Science, vol. 325, pp. 419-422, 2009.

20. G. Gallopn, "Human dimensions of global change: linking the global and the local processes," International social science journal, vol. 43(4), pp. 707-718, 1991.

21. O. Young, F. Berkhout, G. Gallopin, M. Janssen, E. Ostrom, and S. van der Leeuw, "The globalization of socio-ecological systems: an agenda for scientific research," Global Environmental Change, vol. 16(3), pp. 304-316, 2006.

22. D. C. Parker, S. M. Manson, M. A. Janssen, M. J. Hoffmann, and P. Deadman, "Multiagent systems for the simulation of land-use and land-cover change: A review.," Annals of the Association of American Geographers, vol. 93(2), pp. 314-337, 2003.

23. F. Bousquet, O. Barreteau, P. D'Aquino, M. Etienne, S. Boissau, S. Aubert, C. Le Page, D. Babin, and J.-C. Castella, Multi-agent systems and role games: an approach for ecosystem co-management., pp. 248-285. Edward Elgar, 2002.

24. R. Matthews, N. Gilbert, A. Roach, J. Polhill, and N. Gotts, "Agent-based land-use models: a review of applications," Landscape Ecology, vol. 22(10), p. 14471459, 2007.

25. M. Janssen and E. Ostrom, "Empirically based, agent-based models," Ecology and Society, vol. 11(2), p. 37, 2006. 
26. D. Murray-Rust, N. Dendoncker, T. P. Dawson, L. Acosta-Michlik, E. Karali, E. Guillem, and M. Rounsevell, "Conceptualising the analysis of socio-ecological systems through ecosystem services and agent-based modelling," Journal of Land Use Science, vol. 6(2-3), pp. 83-99, 2011.

27. E. Ostrom, "Collective action and the evolution of social norms," The Journal of Economic Perspectives, vol. 14(3), pp. 137-158, 2000.

28. X. Chen, F. Lupi, L. An, R. Sheely, A. Via, and J. Liu, "Agent-based modeling of the effects of social norms on enrollment in payments for ecosystem services," Ecological Modelling, 2011.

29. M. D. A. Rounsevell, B. Pedroli, K.-H. Erb, M. Gramberger, A. G. Busck, H. Haberl, and S. e. a. Kristensen, "Challenges for land system science," Land Use Policy, 2012.

30. N. Becu, "Agent based simulation of a small catchment water management in northern thailand description of the catchscape model.," Ecological Modelling, vol. 170, pp. 319331, 2003.

31. C. Topping, T. Hye, and C. Olesen, "Opening the black box-development, testing and documentation of a mechanistically rich agent-based model," Ecological Modelling, vol. 221(2), pp. 245-255, 2010.

32. S. Lauf, D. Haase, P. Hostert, T. Lakes, and B. Kleinschmit, "Uncovering land-use dynamics driven by human decision-making a combined model approach using cellular automata and system dynamics," Environmental Modelling $\&$ Software, vol. 2728, pp. 71-82, 2012.

33. A. Saltelli, M. Ratto, T. Andres, F. Campolongo, J. Cariboni, D. Gatelli, M. Saisana, and et al., Global sensitivity analysis: the primer. Wiley Online Library, 2008.

34. A. Ligmann-Zielinska and L. Sun, "Applying time-dependent variance-based global sensitivity analysis to represent the dynamics of an agent-based model of land use change," International Journal of Geographical Information Science, vol. 24(12), pp. 1829-1850, 2010.

35. M. Ratto, A. Castelletti, and A. Pagano, "Emulation techniques for the reduction and sensitivity analysis of complex environmental models," Environmental Modelling E Software, 2011.

36. B. de Vries, "Interacting with complex systems: models and games for a sustainable economy," tech. rep., Netherlands Environmental Assessment Agency (PBL)., 2010.

37. S. Kefi, M. Rietkerk, C. L. Alados, Y. Pueyo, A. Papanastasis, V. P. andElAich, and P. C. de Ruiter, "Spatial vegetation patterns and imminent desertification in mediterranean arid ecosystems," Nature, vol. 449, pp. 213-218, 2007.

38. M. Scheffer, Critical Transitions in Nature and Society. Princeton University, 2009.

39. M. Kok, M. Ldeke, T. Sterzel, P. Lucas, C. Walter, P. Janssen, and I. de Soysa, "Quantitative analysis of patterns of vulnerability to global environmental change," tech. rep., PBL/PIK/NTNU Background Studies, 2011.

40. C. Godfray, I. Crute, L. Haddad, D. Lawrence, J. Muir, N. Nisbett, J. Pretty, S. Robinson, C. Toulmin, and R. Whiteley, "The future of the global food system," Philosophical Transactions of the Royal Society B, vol. 365(1554), pp. 2769-2777, 2010.

41. F. Bouwman, B. A., and B. G., "Human alteration of the global nitrogen and phosphorus soil balances for the period 19702050," Global Biogeochemical Cycles, vol. 23, 2009.

42. L. v. Beek, Y. Wada, and M. Bierkens, "Global monthly water stress: 1. water balance and water availability," Water Resource Research, vol. 47, 2011.

43. Y. Wada, L. van Beek, D. Viviroli, H. Drr, R. Weingartner, and M. Bierkens, "Global monthly water stress: 2 . water demand and severity of water stress," Water Resource Research, vol. 47, 2011.

44. A. Voinov and F. Bousquet, "Modelling with stakeholders. special issue," Environmental Modelling \& Software, vol. 25(11), 2010.

45. O. Barreteau, F. Bousquet, and J. Attonaty, "Role-playing games for opening the black box of multi-agent systems: method and lessons of its application to senegal river valley irrigated systems," Journal of artificial societies and social simulation, vol. 4, 2001. 
46. N. Becu, A. Neef, P. Schreinemachers, and C. Sangkapitux, "Participatory computer simulation to support collective decision-making: Potential and limits of stakeholder involvement," Land Use Policy, vol. 25(4), pp. 498-509, 2008.

47. M. Etienne, ed., Companion modelling. A participatory approach to support sustainable development. QUAE, 2011.

48. O. Barreteau, P. W. G. Bots, and K. A. Daniell, "A framework for clarifying participation in participatory research to prevent rejection of participation for bad reasons," Ecology and Society, vol. 15(2), 2010.

49. G. Guariso and H. Werhner, Environmental Decision Support Systems. E. Horwood, 1989.

50. V. Grimm, U. Berger, F. Bastiansen, S. Eliassen, V. Ginot, J. Giske, J. Goss-Custard, T. Grand, S. Heinz, G. Huse, A. Huth, J. Jepsen, C. Jrgensen, W. Mooij, B. Muller, G. Peer, C. Piou, S. Railsback, A. Robbins, M. Robbins, E. Rossmanith, N. Ruger, E. Strand, S. Souissi, R. Stillman, R. Vab, U. Visser, and D. DeAngelis, "A standard protocol for describing individual-based and agent-based models," Ecological Modelling, vol. 198, pp. 115-126, 2006.

51. D. Parker, D. Brown, J. Polhill, S. Manson, and P. Deadman, "Illustrating a new conceptual design pattern for agent-based models and land use via five case studies: The mr potatohead framework," in Agent-based Modellaling in Natural Resource Management (A. Paredes and C. Iglesias, eds.), Pearson Education, 2008.

52. P. Edwards, J. Farrington, C. Mellish, L. Philip, A. Chorley, F. Hielkema, E. Pignotti, R. Reid, J. Polhill, and N. Gotts, "esocial science and evidence-based policy assessment: challenges and solutions.," Social Science Computer Review, vol. 27(4), pp. 553-568, 2009.

53. P. Smits, D. Arctur, R. Atkinson, L. Bargmeyer, B.and Boerboom, S. Browdy, E. Van Praag, G. Hodge, S. Jensen, T. Suha Ulgen, and M. Wilson, "Eye on earth working group 3 technical infrastructure white paper 1: Recommendations for the technical design of a global interoperable information network," tech. rep., Environment Agency Abu Dhabi, 2011.

54. F. Gargiulo, S. Terns, S. Huet, and G. Deffuant, "An iterative approach for generating statistically realistic populations of households," PLoS One, vol. 5(1), 2010.

55. J. Ingram, P. Ericksen, and D. Liverman, eds., Food Security and Global Environmental Change. Earthscan, 2010.

56. R. Berger-Schmitt and H.-H. Noll, "Conceptual framework and structure of a european system of social indicators eureporting. working paper n9.," tech. rep., Centre for Survey Research and Methodology (ZUMA). Social Indicators Department, Mannheim, 2000 .

57. Global Environmental Outlook. Environment for development. United Nations Environment Programme, 2007.

58. A. Harding, S. Kelly, R. Percival, and M. Keegan, "Population ageing and government age pension outlays: Using microsimulation models to inform policy making," tech. rep., Economic and Social Research Institute, Cabinet Office, Government of Japan, 2009.

59. A. Klevmarken and L. Bjrn, Simulating an Ageing Population. A microsimulation approach applied to Sweden. Bingley, Emerald, 2008.

60. A. Zaidi, A. Harding, and P. Williamson, eds., New Frontiers in Microsimulation Modelling. Ashgate, 2009.

61. N. Meadea and I. Towhidul, "Modelling and forecasting the diffusion of innovation a 25-year review," International Journal of Forecasting, vol. 22(3), pp. 519-545, 2006.

62. M. J. O'Brien and S. Shennan, eds., Innovation in cultural systems: contributions from evolutionary anthropology. MIT, 2009.

63. "The state of world fisheries and aquaculture 2002," tech. rep., Fisheries Department, Food and Agriculture Organization of the United Nations, 2002.

64. "Low-income food-deficit countries (lifdc).," tech. rep., Food and Agriculture Organization of the United Nation, 2006. 
65. Y. Chen, X. Li, W. Su, and Y. Li, "Simulating the optimal land-use pattern in the farming-pastoral transitional zone of northern china," Computers, Environment and Urban Systems, vol. 32, pp. 407-414, 2008.

66. R. Burton, "Seeing through the good farmer's eyes: Towards developing an understanding of the social symbolic value of productivist behaviour," Sociologica Ruralis, vol. 44(2), pp. 195-205, 2004.

67. N. Gotts and J. Polhill, "When and how to imitate your neighbours: lessons from and for fearlus," Journal of Artificial Societies and Social Simulation, vol. 12(3), 2009.

68. S. Manson and T. Evans, "Agent-based modeling of deforestation in southern yucatn, mexico, and reforestation in the midwest united states," Proceedings of the National Academy of Sciences, vol. 104(52), pp. 20678-20683, 2007.

69. J. S. Lansing and J. N. Kremer, "Emergent properties of balinese water temple networks: coadaptation on a rugged fitness landscape," in Artificial Life III (C. Langton, ed.), pp. 201-223, Addison-Wesley, 1994.

70. C. Washington-Ottombre, B. Pijanowski, D. Campbell, J. Olson, J. Maitima, A. Musili, T. Kibaki, H. Kaburu, P. Hayombe, E. Owango, B. Irigia, S. Gichere, and A. Mwangi, "Using a role-playing game to inform the development of land-use models for the study of a complex socio-ecological system," Agricultural Systems, vol. 103, pp. 117-125, 2010.

71. D. Parker, "Measuring pattern outcomes in an agent-based model of edge-effect externalities using spatial metrics," Agriculture, Ecosystems and Environment, vol. 101, pp. 223-250, 2004.

72. D. Robinson, D. Brown, D. Parker, P. Schreinemachers, M. Janssen, M. Huigen, H. Wittmer, N. Gotts, P. Promburom, E. Irwin, T. Berger, F. Gatzweiler, and C. Barnaud, "Comparison of empirical methods for building agent-based models in land use science," Journal of Land Use Science, vol. 2, pp. 31-55, 2007.

73. P. Ericksen, B. Stewart, J. Dixon, and D. Barling, Value of a Food System Approach. Earthscan Ltd, 2010.

74. W. Friedland, "Commodity systems analysis: An approach to the sociology of agriculture," Research in Rural Sociology and Development, vol. 1, pp. 221-235, 1984.

75. W. Friedland, "Reprise on commodity systems methodology," International Journal of Sociology and Agriculture, vol. 9(1), pp. 82-103, 2001.

76. J. Henderson, P. Dicken, M. Hess, N. Coe, and H. Yeung, "Global production networks and the analysis of economic development," Review of International Political Economy, vol. 9, pp. 463-464, 2002.

77. H. Friedmann and P. McMichael, "Agriculture and the state system: The rise and decline of national agricultures," Sociologia Ruralis, vol. 29(2), pp. 93-117, 1989.

78. P. J. Ericksen, "Conceptualizing food systems for global environmental change research," Global Environmental Change, vol. 18, pp. 234-245, 2008.

79. J. von Braun and E. Diaz-Bonilla, "Globalization of agriculture and food: Causes, consequences and policy implications.," in Globalization of Food and Agriculture and the Poor (J. von Braun and E. Diaz-Bonilla, eds.), Oxford University Press, 2008.

80. D. W. Cash, W. Adger, F. Berkes, P. Garden, L. Lebel, P. Olsson, P. L., and Y. O., "Scale and cross-scale dynamics: governance and information in a multilevel world," Ecology and Society, vol. 11(2), 2006.

81. A. Sundkvist, R. Milestad, and A. Jansson, "On the importance of tightening feedback loops for sustainable development of food systems," Food Policy, vol. 30, pp. 224-239, 2005.

82. L. C. Dreyer, M. Z. Hauschild, and J. Schierbeck, "A framework for social life cycle impact assessment," The International Journal of Life Cycle Assessment, vol. 11, pp. 88-97, 2005.

83. J. N. Galloway, M. Burke, G. E. Bradford, R. Naylor, W. Falcon, A. K. Chapagain, J. C. Gaskell, E. McCullough, H. A. Mooney, K. L. L. Oleson, H. Steinfeld, T. Wassenaar, and V. Smil, "International trade in meat: The tip of the porkchop," AMBIO: A Journal of the Human Environment, vol. 36(8), pp. 622-629, 2007.

84. L. Mil i Canals, J. Chenoweth, A. Chapagain, S. Orr, A. Antn, and R. Clift, "Assessing freshwater use impacts in lca: Part iinventory modelling and characterisation 
factors for the main impact pathways.," International Journal of Life Cycle Assessment, vol. 14(1), pp. 28-42, 2009.

85. D. Lyons, M. Rice, and R. Wachal, "Circuits of scrap: closed loop industrial ecosystems and the geography of us international recyclable material flows 1995 2005," The Geographical Journal, vol. 175, pp. 286-300, 2009.

86. F. Geels, "Technological transitions as evolutionary reconfiguration processes: a multilevel perspective and a case-study," Research Policy, vol. 31, pp. 1257-1274, 2002.

87. M. Meybeck and C. Vrsmarty, "The integrity of river and drainage basin systems: Challenges from environmental changes," in Vegetation, Water, Humans and the Climate: a New Perspective on an Interactive System (P. Kabat, M. Claussen, P. Dirmeyer, J. Gash, L. Bravo de Guenni, M. Meybeck, C. Pielke, R.S.and Vrsmarty, R. Hutjes, and S. Ltkemeier, eds.), IGBP Global Change Series, International Geosphere-Biosphere Programme and Springer-Verlag, Berlin, 2004.

88. I. Shiklomanov, "World water resources: Modern assessment and outlook for the 21st century.," tech. rep., IHP-UNESCO, 1999.

89. "Coping with water scarcity: challenge of the twenty-first century," tech. rep., UN Water day, 2007.

90. World Health Organization and United Nations Childrens Fund Joint Monitoring Programme for water supply and sanitation (JMP). Progress on sanitation and drinking water2010 update. WHO Press, 2010.

91. S. Zacharias, H. Bogen, L. S. M. Mauder, R. Fu, T. Ptz, M. Frenzel, M. Schwank, C. Baessler, K. Butterbach-Bahl, O. Bens, E. Borg, A. Brauer, P. Dietrich, I. Hajnsek, G. Helle, R. Kiese, H. Kunstmann, S. Klotz, J. C. Munch, H. Papen, E. Priesack, H. P. S. R. Steinbrecher, U. Rosenbaum, G. Teutscha, and H. Vereeckenb, "A network of terrestrial environmental observatories in germany," Vadose Zone Journal, vol. 10(3), pp. 955-973, 2011.

92. T. Kalbacher, J. Delfs, H. Shao, W. Wang, M. Walther, L. Samaniego, C. Schneider, R. Kumar, A. Musolff, F. Centler, and et al., "The iwas-toolbox: Software coupling for an integrated water resources management," Environmental Earth Sciences, vol. 65(5), pp. 1367-1380, 2012.

93. E. Kalbus, T. Kalbacher, O. Kolditz, E. Krueger, J. Seegert, G. Roestel, G. Teutsch, D. Borchardt, and P. Krebs, "Iwas - integrated water resources management under different hydrological, climatic and socio-economic conditions," Environmental Earth Sciences, vol. 65(5), pp. 1363-1366, 2012.

94. W. Medema, B. S. McIntosh, and P. J. Jeffrey, "From premise to practice: a critical assessment of integrated water resources management and adaptive management approaches in the water sector," Ecology and Society, vol. 13(2), 2008.

95. B. Walker, "Resilience, adaptability, and transformability in the goulburn-broken catchment, australia," Ecology and Society, vol. 14(12), 2009.

96. R. Leakey and R. Lewin, The Sixth Extinction: Patterns of Life and the Future of Humankind. Anchor Pub, 1996.

97. H. Willer and L. Kilcher, The World of Organic Agriculture Statistics and Emerging Trends. IFOAM, 2009.

98. M. Miles and J. Covin, "Environmental marketing: a source of reputational, competitive, and financial advantage," . Journal of Business Ethics, vol. 23(3), pp. 299-311, 2000 .

99. H. M. Pereira, P. W. Leadley, V. Proena, R. Alkemade, J. P. W. Scharlemann, J. F. Fernandez-Manjarrs, M. B. Arajo, P. Balvanera, R. Biggs, W. W. L. Cheung, L. Chini, H. D. Cooper, E. L. Gilman, S. Gunette, G. C. Hurtt, H. P. Huntington, G. M. Mace, T. Oberdorff, C. Revenga, P. Rodrigues, R. J. Scholes, U. R. Sumaila, and M. Walpole, "Scenarios for global biodiversity in the 21st century," Science, vol. 330(6010), pp. 1496-1501, 2010.

100. M. Felici, V. Lucarini, A. Speranza, and A. Vitolo, "Extreme value statistics of the total energy in an intermediate-complexity model of the midlatitude atmospheric jet. part i : Stationary case.," Journal of the Atmospheric Sciences, vol. 64, pp. 2137-2158, 2007. 
101. M. Felici, V. Lucarini, A. Speranza, and A. Vitolo, "Extreme value statistics of the total energy inan intermediate-complexity model of the midlatitude atmospheric jet. part ii : Trend detection andassessment.," Journal of the Atmospheric Sciences, vol. 64, pp. 2159-2175, 2007.

102. P. C. D. Milly, J. Betancourt, M. Falkenmark, R. M. Hirsch, Z. W. Kundzewicz, L. D. P., and R. J. Stouffer, "Stationarity is dead: Whither water management?," Science, vol. 319, pp. 573-574, 2008.

103. R. W. Katz, M. B. Parlange, and P. Naveau, "Statistics of extremes in hydrology," Advances in Water Resources, vol. 25, pp. 1287-1304, 2002.

104. B. T. Werner and D. E. McNamara, "Dynamics of coupled human-landscape systems," Geomorphology, vol. 91(3-4), pp. 393-407, 2007.

105. J. Posey, "The determinants of vulnerability and adaptive capacity at the municipal level: Evidence from floodplain management programs in the united states," Global Environmental Change, vol. 19, pp. 482-493, 2009.

106. C. Fishman, The Big Thirst: The Secret Life and Trubulent Futre of Water. Simon \& Schuster, 2011

107. C. Londono and A. W. R. Ando, "Valuing preferences over storm water management outcomes given state-dependent preferences and heterogeneous status quo," in Annual Meeting of Agricultural and Applied Economics Association, 2011.

108. F. Biermann, M. Betsill, J. Gupta, N. Kanie, L. Lebel, D. Liverman, H. Schroeder, and B. Siebenhner, "Earth system governance: People, places and the planet.," tech. rep., IHDP: The Earth System Governance Project, 2009.

109. R. Bradfield, G. Wright, G. Burt, G. andCairns, and K. Van Der Heijden, "The origins and evolution of scenario techniques in long range business planning," Futures, vol. 37(8), pp. 785-812, 2005.

110. M. D. A. Rounsevell and M. J. Metzger, Developing qualitative scenario storylines for environmental change assessment. Wiley Interdisciplinary Reviews: Climate Change, 2010.

111. S. Bankes, "Tools and techniques for developing policies for complex and uncertain systems," Proceedings of the National Academy of Sciences, vol. 99, pp. 7263-7266, 2002.

112. B. de Vries, Scenarios: guidance for an uncertain and complex world?, ch. 19, pp. 378398. MIT Press, 2007.

113. V. Grimm and J. Calabrese, What is Resilience ? A short introduction, pp. 3-14. Springer, 2011.

114. C. Holling, "Resilience and stability of ecological systems," Annual Review of Ecology and Systematics, vol. 4, pp. 1-24, 1973.

115. L. Gunderson, C. Allen, and C. Holling, Foundations of ecological resilience. Paperback, 2009.

116. G. Brundtland, Our common Future. Report of the World Commission on Environment and Development. Oxford University Press, 1987.

117. C. Perring, "Resilience and sustainable development," Environment and Development Economics, vol. 11, pp. 417-427, 2004.

118. F. S. Brand and K. Jax, "Focusing the meaning(s) of resilience: resilience as a descriptive concept and a boundary object.," Ecology and Society, vol. 12(1), 2007.

119. N. Gotts, "Resilience, panarchy, and world-systems analysis," Ecology and Society, vol. 12(1), 2007.

120. B. Walker, S. Carpenter, J. Anderies, N. Abel, G. Cumming, M. Janssen, L. Lebel, J. Norberg, G. Peterson, and R. Pritchard, "Resilience management in social-ecological systems: a working hypothesis for a participatory approach," Conservation Ecology, vol. 6(14), 2002.

121. S. Martin, "The cost of restoration as a way of defining resilience: a viability approach applied to a model of lake eutrophication," Ecology and Society, vol. 9(2), 2004.

122. G. Deffuant and N. Gilbert, eds., Viability and Resilience of Complex Systems; Concepts, Methods and Case Studies from Ecology and Society. Springer, 2011. 
Author-created version of the article published in European Physical Journal Special Topics, 2012, 214, 519-545 The final publication is available at www.epj.org. DOI : 10.1140/epjst/e2012-01704-2

123. M. Ajmone-Marsan, D. Arrowsmith, W. Breymann, O. Fritz, D. Helbing, M. Masera, A. Mengolini, and A. Carbone, "The emerging energy web," Eur. Phys. J. Special Topics, vol. 214, 2012. 